\section{Lucky winners announced}

\section{Tokyo}

As in previous years, the biosciences and in particular molecular biology take by far the largest share of the "special distinguished" and "priority" grants announced two weeks ago by Japan's Ministry of Education, Science and Culture (MESC). But astrophysics and oceanography also feature prominently in the awards which are the biggest and most respected in MESC's grant repertoire.

The special distinguished grants, which go to individuals for "internationally recognized research that is likely to produce outstanding results", take effect immediately. The priority grants just announced, which support large teams of scientists, begin next fiscal year and their size is still subject to negotiations with the Ministry of Finance. Nevertheless, the amount of money awarded is usually fairly close to that requested.

The budget for priority grants has risen rapidly since they were introduced in 1986 and they now account for over a quarter (27 per cent) of MESC's annual research grant budget of about $¥ 50,000$ million (\$340 million). Twenty-two grants were awarded in this category together with eleven special distinguished grants.

Minoru Kanehisa of Kyoto University's Institute for Chemical Research is set to get a large priority grant to develop computer techniques for analysing DNA SUPERPHENIX

\section{In trouble again}

\section{Paris}

THE French 1,200 MW fast-breeder reactor, Superphénix, near the Swiss burder, has been shut down again, this time because of oxidation of its liquid sodium coolant. The incident, which is rated ' 2 ' on a six-point risk scale for nuclear installations, is due to an influx of air into the cooling circuits, rendering the sodium more viscous and less efficient as a coolant.

The present shut-down, which is expected to last several months, means that the prototype reactor will have been operating for only just over half the time since it first came on stream in January 1986. In 1987 a leak in the reservoir containing the liquid sodium led to the reactor being shut down for more than $\mathbf{1 8}$ months. In both incidents, the reactor continued to operate for over two weeks before engineers were able to conclude from monitoring data that there was a serious fault. The government service for safety in nuclear installations (SCSIN), part of the industry ministry, has ordered an inquiry into the latest incident and expects to develop new recommendations on monitoring procedures. Peter Coles sequences of human and other genome data. Kanehisa is on an MESC committee that is planning to establish a human genome project in Japan in the next year or so, and his grant request of $¥ 850$ million (\$5.7 million) over five years will give a significant boost to Japan's current small financial commitment to human genome research.

One of the biggest priority grants (a request for $¥ 1,180$ million for three years) goes to Hideyuki Ogawa of Osaka University for a project intended to elucidate the molecular mechanisms of genetic recombination by focusing on how homologous DNA molecules recognize each other.

Many of the awards in the field of chemistry have biological themes. Tsujiaki Hata of the department of life chemistry at Tokyo Institute of Technology gets a priority grant with a request for $¥ 550$ million over three years to develop new methods for the large-scale synthesis of oligonucleotides.

Kazuhiro Maruyama of the department of chemistry at Kyoto University wins a special distinguished grant of $¥ 200$ million over four years to synthesize and characterize an artificial photosynthetic reaction centre. And Yukito Murakami of the department of organic synthesis at Kyushu University will receive $¥ 205$ million in the same category for the molecular design of artificial enzyme systems.

The biggest special distinguished grant in biology ( $¥ 238$ million for five years) goes to Katsuhiko Mikoshiba at the Institute for Protein Research at Osaka University for his pioneering research on the $\mathrm{InsP}_{3}$ (inositol 1,4,5-trisphosphate) receptor in neurons and its role in neuronal signal transduction in the brain (see Nature 342, 32; 1989). Takeyuki Wakabayashi of Tokyo University wins his second special distinguished grant, this time $¥ 199$ million over four years, to continue his research on the molecular mechanism of muscle contraction using protein engineering and cryo-electron microscopy.

In oceanography, Asahiko Taira of the Ocean Research Institute at Tokyo University is awarded a special distinguished grant of $¥ 210$ million for three years to produce high-resolution seismic images of the Izu-Ogasawara arc system. A team headed by his colleague Hitoshi Sakai at the same institute will examine ocean fluxes of terrestrial and biologically produced materials in the western North Pacific with a three-year priority grant provisionally set at $¥ 640$ million.

Some of the largest grants go to astrophysics. Norio Kaifu of the National Astronomical Observatory heads a team that will set out over the next four years to understand the elementary process, circulation and evolution of interstellar matter with a proposed priority grant of $¥ 970$ million. Takashi Nakamura of the Yukawa Institute for Theoretical Physics at Kyoto University has requested a similar amount ( $¥ 930$ million for four years) for his team to try to be the first to detect gravity waves, possibly from the formation of a black hole or neutron star. The biggest special distinguished grant of all ( $¥ 255$ million for five years) goes to Kimio Niwa of Nagoya University, who will try to determine the mass of the tau neutrino.

Notable by its absence among the awards is cold fusion. Despite persistent rumours that Japan is carrying out a coordinated research effort in this field, MESC's only award for cold fusion research is a small grant of $¥ 10$ million $(\$ 87,000)$ to Hideo Ikegami of the National Institution for Fusion Science.

David Swinbanks

\section{More grant awards}

\section{Tokyo}

JAPAN's Ministry of Education, Science and Culture (MESC) is no longer the only body to award big grants to university researchers.

Within days of MESC announcing its biggest grants, the New Energy and Industrial Technology Development Organization (NEDO), an organization affiliated with the Ministry of International Trade and Industry (MITI), awarded six large grants to international teams of university researchers for investigation of new materials. The NEDO grants and MITI's related Human Frontier Science Program represent a new and welcome source of money for Japan's fund-starved university researchers.

The NEDO grant programme was established in 1988 and awarded the first international grants for research on the brain and molecular biology under Japan's Human Frontier Science Program. Responsibility for Frontier grants has now been transfered to the Human Frontier Foundation in Strasbourg. But NEDO continues to award similar international grants for research on new materials.

Last week's awards, which are each worth about $¥ 30$ million $(\$ 200,000$ ) a year and can be extended up to three years, go to six teams comprising 31 researchers from Japan (15), the United States (9), France (3), West Germany (3) and the United Kingdom (1).

At present the NEDO grants are restricted to material science but Masami Takayasu of NEDO says that NEDO is on the lookout for other suitable areas of research to support and would "welcome suggestions".

David Swinbanks 